\title{
Toward sustainability with the coordinated freight distribution of municipal goods
}

Maria Björklund and Sara Gustafsson

The self-archived postprint version of this journal article is available at Linköping University Institutional Repository (DiVA):

http:/ / urn.kb.se/ resolve?urn=urn:nbn:se:liu:diva- 114635

N.B.: When citing this work, cite the original publication.

Björklund, M., Gustafsson, S., (2015), Towards sustainability with the coordinated freight distribution of municipal goods, J ournal of Cleaner Production, 98, 194-204.

https:// doi.org/ 10.1016/j.jclepro.2014.10.043

Original publication available at:

https:// doi.org/ 10.1016/j.jclepro.2014.10.043

Copyright: Elsevier

http:// www.elsevier.com/

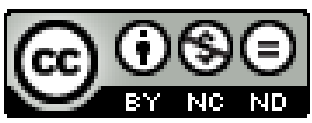




\title{
Toward Sustainability with the Coordinated Freight Distribution of Municipal Goods
}

Keywords: Sustainable urban development, purchasing, collaboration and knowledge dissemination, municipalities, coordinated freight distribution

\begin{abstract}
Municipalities play an important role in the development of sustainable societies, particularly by way of public procurement. Within this area, municipal governments can significantly impact the environment by placing environment-conscious demands on the products and services purchased. At the same time, municipalities are largely responsible when it comes to decreasing the fastest growing source of $\mathrm{CO}_{2}$ emissions in urban areas: road transport. Yet, while much has been done to curb the environmental impact of passenger transport, freight transport seems to have been nearly forgotten. Some Swedish municipalities have set a good example by coordinating the distribution of goods to their facilities and by separating the purchases of goods from those of distribution services. Although municipalities claim that cooperation and knowledge dissemination are central to developing sustainability management, it remains unclear how such should be applied to coordinated urban freight distribution. This paper thus aims to describe and analyse activities in Swedish municipalities' developmental processes of promoting the coordinated freight distribution of goods, in order to identify which activities of knowledge dissemination and collaboration should be prioritised. Empirical data were gathered from interviews, the Internet, and brochures for initiatives taken by Swedish municipalities. Results indicate that the initiatives demonstrate several similarities and differences, as well as provide examples of how knowledge can be integrated into municipal organisation. Above all, results indicate a need for increased collaboration among actors to make freight transport in Swedish cities more efficient, as well as that increased knowledge transfer can help municipalities to overcome several of their weaknesses.
\end{abstract}




\section{Introduction}

Municipalities (i.e. local authorities) are important actors in the struggle for more sustainable development (Lindqvist and von Malmborg, 2004; UNCED, 1993), while the world's cities have been identified as future key players in the transition toward, for example, low carbon societies (Khan, 2013). Municipalities bear significant responsibility not only as service providers and important democratic actors, but also as crucial mediators between citizens and both national and international public bodies. Since 1990s, Swedish municipalities in particular have expanded their responsibility in sustainability management, from primarily fulfilling national legislation to also including more selfmotivated initiatives (Emilsson and Hjelm, 2009), which has, among other things, meant increased cooperation with local stakeholders.

This expansion in responsibility can also extend to how municipalities address freight distribution issues in urban areas (Lindholm, 2012). The distribution of goods in cities induces different negative impacts upon sustainability, including increased emissions, congestion, noise, and accidents (Benjelloun et al., 2010; Kennedy et al., 2005; OECD, 2003). In fact, road transport is responsible for $40 \%$ of $\mathrm{CO}_{2}$ emissions in cities (EC, 2007) and is the fastest growing source of $\mathrm{CO}_{2}$ emissions in urban environments (Dablanc, 2007). Among all transport, that of municipal goods (e.g. food and equipment to schools, day care centres, and offices) has traditionally been organised around the origin (e.g. retail chains, suppliers, or logistics service providers' distribution centres) instead of the destination (Moen, 2013). As a result, municipalities' large purchases of goods can contribute to environmentally, economically, and even socially inefficient urban freight distribution.

Municipalities have more often viewed the flow of goods into urban areas to be problematic than essential. They have also often viewed logistics service providers (LSPs) to be obstacles during policy implementation instead of co-actors (Stathopoulos et al., 2012). However, these dynamics are set to change. To a larger extent than a few years ago, several Swedish municipalities have implemented changes in distribution, particularly the increased use of coordinated freight distribution solutions and improved procurement practices of distribution services.

Although municipalities generally claim that cooperation and knowledge dissemination are central to developing sustainability management (Emilsson and Hjelm, 2009), it remains unclear how these aspects should be applied regarding coordinated urban freight distribution. At the same time, knowledge of successful collaboration in city logistics initiatives remains limited (Martinsen et al., 2012), details about who to include among different actors and how to include them continue to be blurry, and few studies have considered stakeholder relationships, let alone examined them (Martinsen et al., 2012; Taniguchi and Tamagawa, 2005). In response, this paper illuminates how knowledge is disseminated both within municipalities and between them and their stakeholders (e.g. LSPs) in the development of environment-conscious initiatives. In doing so, it aims to describe and analyse activities in Swedish municipalities' developmental processes of promoting the coordinated freight distribution of their own goods, and to identify important activities with regard to knowledge dissemination and collaboration.

\section{Methodology}

Data collection for this study was designed to follow an approach involving two interdependent steps, including a general overview of municipal co-distribution initiatives in Sweden and a more in-depth 
study of a few selected cases. In parallel, we conducted a literature review to identify the current status of municipalities' solutions for the coordinated freight distribution of municipal goods.

The literature review returned very few articles regarding municipal coordinated distribution published in scientific journals. Most returns related to logistics companies and goods transport in a more general sense. At the same time, hardly any literature has addressed municipalities' role in consolidating the transport of commercial goods (Martinsen et al., 2012). Since our literature search had to be broadened, we sought related literature regarding public procurement, city logistics, and municipal environmental management, as a means to identify issues possibly related to urban distribution and transport purchasing.

Empirical data were collected from nine Swedish municipalities: Borlänge, Halmstad, Katrineholm, Eskilstuna, Södertörn, Nacka, Värnamo, Växjö, and Uppsala. These cities were identified by an online search using the search combinations "municipality and transport" and "municipality and distribution". Important selection criteria were that the municipality (1) had a permanent coordinated freight distribution solution (i.e. neither forthcoming and abandoned solutions nor any test or pilot projects); (2) had aims and goals concerning environmental, social, and economic issues; and (3) had taken responsive actions such as implementing a coordinated distribution centre (CDC).

Secondary empirical data were gathered via an online investigation of the same nine municipalities' websites, which were scanned for information regarding coordinated freight distribution. The amount of documentation describing the municipalities' initiatives varied between cities, though many of them had some kind of baseline report, in most of which consultants had analysed the preconditions for coordinating freight distribution and whether the municipality was likely to benefit from such an arrangement. We also located presentations used during the implementation process (e.g. stakeholders' dialogues, training materials) as well as statistics regarding transport patterns.

Though other actors participate from time to time in implementing coordinated freight distribution solutions to support sustainable development in urban areas, municipalities are constant players. To gain a deeper understanding of municipal collaboration and knowledge exchange with other actors during the development process, interviews with project leaders in five of the above Swedish municipalities (Table 1 ) were conducted. These municipalities were chosen since they had successfully implemented fully operational initiatives and since their consolidation initiatives differentiated from each other. Semi-structured interviews were conducted according on an interview guide with openended questions, as was considered to be useful by Ely et al. (1993), among others, in inviting and collecting as much information as possible. The interviews chiefly addressed all phases of municipalities' developmental processes as a way to obtain a deeper understanding of the initiatives and their outcomes. The interviews also aimed to illuminate the knowledge transfer and identify actors involved throughout the implementation process. The interviews were transcribed shortly after the interviews themselves, and the transcripts were sent to the respondents for verification.

Identifying municipal officers responsible for action targeting freight transport in Swedish municipalities has proven difficult during earlier interviews. A recent survey of all Swedish municipalities by Lindholm and Blinge (2014), resulted in the identification of only three municipalities with at least one official responsible for freight transport. In our study's process of identifying respondents, we examined webpages, reports, and presentations identified during secondary empirical investigation for relevant contact information. In our interviews, we asked respondents to 
provide additional information, if possible, and consulted with receptionists at municipal switchboards. Despite these efforts, only one respondent from each municipality studied was identified as having significant insight into the process. However, considering that freight transport was only recently recognised as an important municipal responsibility, we were not surprised by these circumstances. During interviews, though we also requested additional written information regarding the initiatives, no information save that already found during the online review was made available.

The validity and reliability of the information gained from these interviews remain questionable. For one, the municipalities remained interested in displaying exemplariness in the processes under study for reasons of setting a good example. However, activities regarding information exchange and municipalities' internal knowledge accumulation were seldom clarified in such marketing, which thereby made our study's data collection more susceptible to biased responses. From another perspective, stakeholder collaboration is important in these activities, which recommends the inclusion of other stakeholders' views. Since each municipality is the only constant player, the views of other actors were captured via secondary data collection involving reports and publications, among other documentation. No differences in views were identified; instead, some statements from LSPs complement the views of the municipalities. To further complicate these results, the initiatives studied commenced at different times. For instance, though one municipality wanted to use ICT in 1999, the technology was not sufficiently developed at the time; other strategies have gone into effect too recently for any meaningful follow-up. In spite of these and other concerns, discussions of these results during presentations of the research at two scientific international conferences contributed to this paper's development.

\subsection{General Description of Cases in Interviews}

The results and discussion of this paper focus chiefly on findings concerning the municipalities of Borlänge, Eskilstuna, Katrineholm, Södertörn, and Värnamo. This section provides a general overview of these municipalities' approaches to and processes of establishing CDCs and changed purchasing performance. 
Table 1. General characteristics of Borlänge, Eskilstuna, Katrineholm, Södertörn, and Värnamo. (Abbreviations: SALAR: Swedish Association for Local Authorities and Regions; EMS: Environmental Management System; CDC: Coordinated Distribution Centre.)

\begin{tabular}{|c|c|c|c|c|c|}
\hline $\begin{array}{l}\text { Population } \\
\text { (Statistics Sweden, } \\
\text { 2013) }\end{array}$ & $\begin{array}{l}\text { Borlänge etc } \\
\text { Borlänge (49 323) } \\
\text { Gagnef (10 097) } \\
\text { Säter (11 000) } \\
\text { Smedjebacken } \\
(10702)\end{array}$ & $\begin{array}{l}\text { Katrineholm } \\
32409\end{array}$ & $\begin{array}{l}\text { Värnamo } \\
32934\end{array}$ & $\begin{array}{l}\text { Södertörn etc } \\
\text { Botkyrka (87 580) } \\
\text { Haninge (80 932) } \\
\text { Huddinge (102 557) } \\
\text { Nykvarn (9 523) } \\
\text { Nynäshamn (26796) } \\
\text { Salem (16 001) } \\
\text { Södertälje (91 072) } \\
\text { Tyresö (44281) }\end{array}$ & $\begin{array}{l}\text { Eskilstuna } \\
99729\end{array}$ \\
\hline $\begin{array}{l}\text { Classification of } \\
\text { municipality } \\
\text { (SALAR, 2011) }\end{array}$ & $\begin{array}{l}\text { Borlänge: } \\
\text { Municipality in } \\
\text { densely populated } \\
\text { region } \\
\text { Gagnef, Säter, } \\
\text { Smedjebacken: } \\
\text { Commuter } \\
\text { municipalities }\end{array}$ & $\begin{array}{l}\text { Municipality } \\
\text { in densely } \\
\text { populated } \\
\text { region }\end{array}$ & $\begin{array}{l}\text { Manufacturing } \\
\text { municipality }\end{array}$ & $\begin{array}{l}\text { Suburban } \\
\text { municipalities to } \\
\text { large cities }\end{array}$ & Large city \\
\hline $\begin{array}{l}\text { Year of EMS } \\
\text { implementation }\end{array}$ & $\begin{array}{l}1999 \text { (Borlänge) } \\
1997 \text { (Smedjebacken) }\end{array}$ & 1997 & - & $\begin{array}{l}1996 \text { (Botkyrka) } \\
1997 \text { (Huddinge) } \\
2000 \text { (Södertälje) }\end{array}$ & 2000 \\
\hline $\begin{array}{l}\text { Year of UCC } \\
\text { implementation }\end{array}$ & 1999 & 2007 & 2009 & Planned 2014 & 2014 \\
\hline $\begin{array}{l}\text { Number of } \\
\text { goods' recipients }\end{array}$ & $\begin{array}{l}125 \text { (Borlänge) } 18 \\
\text { (Gagnef), } 18 \text { (Säter) } \\
21 \text { (Smedjebacken) }\end{array}$ & 90 & $145-150$ & 1000 & $\begin{array}{l}100 \text { (2014) } \\
600 \text { (full } \\
\text { scale 2015) }\end{array}$ \\
\hline
\end{tabular}

\subsubsection{The Case of Borlänge}

In 1999, three neighbouring cities-Borlänge, Gagnef, and Säter-agreed to change their distribution structure and separate food purchases from purchases of logistics services. In 2000, the municipality of Smedjebacken also became involved in the initiative. In the following description, however, we refer to all municipalities as Borlänge, which is the largest municipality of the four and the primary actor in the initiative. To mutually manage all food delivery and transportation, a shared CDC was established, the operation of which and the transportation services involved were purchased from an LSP. Both large and smaller consumer packages were integrated into the shared structure, and a central ordering body connected to the receivers by an electronic ordering system was installed. Three separate purchases were made: one for food, one for distribution, and one for a platform for electronic purchases. Each receiver had a predetermined day of the week for deliveries, as well as two additional days if needed. Since four distribution centres were already established in the city of Borlänge, the group of cities saw no need to build a new and costly CDC. One initial target of the project was to increase competition among suppliers, since several small suppliers did not have sufficient logistics services for inclusion in the tender. Other objectives were to cut costs, improve the municipal environment, and increase safety at delivery points such as schoolyards.

\subsubsection{The Case of Värnamo}

In 2009, Värnamo initiated a process to develop a more coordinated approach to municipal transport. The initiative's chief objectives were to ameliorate the city's environmental situation and improve road 
safety. An economic analysis conducted by a consultancy firm revealed the potential benefits of establishing a CDC outside of the city (Värnamo kommun, 2009). Upon deciding to establish a CDC, Värnamo recruited a logistics manager responsible for developing the municipality's coordinated transport initiative. The manager was delegated the operational responsibility of developing the new initiative and the facilities to be built for such a purpose. Once the CDC was established, its operation was outsourced to an entrepreneur. Värnamo's initiative included transports for the whole municipality, while issues such as building material and facility furniture were excluded. Food was initially excluded as well, due to the special conditions it required. In 2011, however, ready meals were added to the list of CDC transports. These meals were delivered daily, while other foods were delivered once per week.

\subsubsection{The Case of Katrineholm}

In 2007, Katrineholm's division of food delivery and division of transport (of letters) were merged during municipal reorganisation. Once the merged divisions realised that a coordinated approach to transport would make their work more efficient, a CDC was established, with a transport division as an affiliate. Katrineholm's initiative was partly influenced by local authorities' commitment to decreasing citywide deliveries to schools and other units with heavy trucks. The initiative was seen as an integral part-even within an existing budget-of the municipality's everyday business encompassing food delivery, parcels, and letters, both internal and external. Katrineholm's electronic purchasing system, which had to be adapted to the new distribution approach, was connected to the CDC to further streamline transports. Though these facilities had not been optimised for such activity upon the initiative's being developed and implemented, during the developmental process the facilities have been adapted to meet the needs of goods requiring reloading and/or redistribution.

\subsubsection{The Case of Södertörn}

At the end of 2013, the council boards of eight neighbouring municipalities (Table 1 ) in south Stockholm (i.e. Södertörn) began to collaboratively implement a shared CDC for transports to their facilities. The initiative was fully implemented during fall 2014. Considering the large number of recipients $(1,000)$, freight volumes, and municipalities involved, this initiative is so far the largest for the coordinated distribution to Swedish municipal facilities. The chief drivers for implementing this coordinated distribution were to reduce the number of transports, curb the environmental impact of, for example, $\mathrm{CO}_{2}, \mathrm{NO}_{x}$, and particulate matter, increase traffic safety, and improve receiver work environments due to fewer disturbing activities regarding the reception of goods. An analysis conducted by a consultancy firm revealed the substantial environmental and economic benefits of the initiative, further encouraging the plan to purchase the logistics service and implement the solution by mid-2013. In 2017, all contracts with goods suppliers will be adjusted to accommodate the CDC transport solution, and the initiative will become fully operational.

\subsubsection{The Case of Eskilstuna}

Eskilstuna recognised the potential benefits of implementing a CDC as early as 2010 . Two attempts to purchase the logistics service were made, neither of which succeeded. During the third attempt, the municipality became owner of a terminal, which it decided to run as part of its solution. Transport services were purchased, and the initiative started running on a small scale in September 2014. The wholesale service (e.g. coordinate of the supply and demand, store and prepare deliveries) was purchased, and the municipality signed contracts with individual product suppliers directly. The need for storage space and handling in the municipality's terminal has therefore decreased. For Eskilstuna, 
the primary aims in implementing coordinated distribution were to decrease the environmental impact and improve traffic safety at the receivers. As the implementation took shape, the municipality also identified potential economic gains and improved delivery service and work environment for receivers as important goals. Approximately 30 people have been involved in this process, including a steering group (e.g. a logistics coordinator, food coordinator, an agent of the purchasing department, and an agent responsible for the kitchens at the receivers). At different phases and on a more needto-know basis, the project has involved people from units responsible for maps and GIS, environmental strategy, economics, HR management, and trade organisation etc.

\subsection{Structuring and Analysing Data}

Several perspectives and approaches are available to structure and analyse activities regarding, for example, knowledge and information exchange related to the developmental process of consolidated urban distribution. For some time, a wide range of environmental management and assessment tools, initiatives, and approaches developed since the early 1990s have been available to support organisations' environmental management (English 1999; Levett, 1997). Some tools are more closely related to procedures (e.g. standardised environmental management systems [EMS]) while others more often concern measuring and monitoring environmental status with certain indicators (Levett, 1997). In relation to the purpose and scope of the present paper, we focus on procedures and management, but not measurement. For this, the process management approach titled Plan, Do, Study, Act (PDSA) was considered to be an appropriate tool, as will be argued below. Emerging out of quality management (Deming, 1982), the PDSA approach was originally launched as the PDCA cycle, for which ' $C$ ' stood for 'Control', though it was eventually changed to ' $S$ ' for 'Study' (Gupta, 2006). In the Plan phase of the PDSA, an organisation maps its baseline level of a certain aspect-in the case of environmental management, environmental performance (ISO, 2004). Mapping and analysing the current practice helps the organisation to understand potential areas for improvement and constitutes a point of departure for setting both objectives and targets and for designing action plans. In the Do phase, the management system (i.e. initiative) is implemented, for which the chief task is to integrate the action plans into the daily work of the organisation by applying, for example, instructions and routines. The Study phase focuses on evaluating and auditing whether the management system operates as planned. In the final phase of the PDSA cycle-the Act phase-management decides what to change in order to achieve further improvement. Feedback loops during the different phases and at different organisational levels are inherent features of the PDSA cycle connected to learning and understanding the chosen approach in different ways and, perhaps, to reconsidering the concept built on earlier experiences.

We chose the PDSA approach for our analytical model because it provides a thorough picture of management practices and a systematic, effective tool for describing the different stages in any developmental process. However, its appropriateness could be questioned, and several other models are available that could have been used. Since we see purchasing as a significant environmental aspect of municipalities and since many Swedish and European municipalities, among others, use EMSs to manage their environmental impact, we considered PDSA to be an applicable approach relevant and well-connected to both overall municipal management and general purchasing activity. In this paper, we also use the model as a means of visualising which communication and knowledge transfer that can be connected to which steps in the cycle. Adopting a cyclic approach to purchasing and freight planning is important in order to continually improve and learn from earlier experiences. By extension, 
doing so could also contribute to more effective, efficient urban distribution and enhance more sustainable transport.

\section{Frame of Reference}

In this study, our frame of reference begins by elaborating the role of municipalities in urban freight transport. Coordinated freight distribution is characterised both by the use of a terminal to consolidate the goods distributed to municipal facilities and by changed purchasing performance-two areas that are here addressed. Lastly, important aspects regarding municipal environmental management are identified.

\subsection{The Role of Municipalities in Sustainable Urban Freight Distribution}

Municipalities can set good examples when it comes to supporting and adapting more efficient and environmentally friendly freight supply within their districts. Traditionally, municipalities have focused on the rules and regulations that influence the flow of goods (Patier and Browne, 2010), as well as on the development and monitoring of regulations and, more specifically, that certain directives (e.g. those of the EC) are met (Benjelloun et al., 2010). Examples of freight-related aspects regulated by municipalities include location and number of loading zones, demands upon environmentally preferable designs and techniques, and vehicles' access to certain areas of the city.

Municipalities not only regulate transport within their geographical area, but are directly or indirectly influence the need for such transport. For example, municipalities are responsible for waste management (Lindqvist and von Malmborg, 2004), for which urban transportation can have a major environmental impact (Eriksson et al., 2005; Moen, 2013). Furthermore, as do large companies, municipalities receive a significant number of goods (e.g. letters, office items, food, and furniture), suggesting a substantial demand for transport within their districts. Though the need for transport derives from consumption, transport within urban areas is commonly organised from the perspective of the sender (e.g. retail chains, suppliers, and/or LSPs) (van Rooijen and Quak, 2010). As a consequence, freight to one receiver could be distributed by different LSPs. Among these circumstances' other implications, it is generally important to understand the demand for goods and services in order to make transport more sustainable (Allen and Browne, 2010; Behrends et al., 2008).

Many Swedish municipalities have voluntarily begun to extend their responsibility for sustainability in order to set a good example, create legitimacy, and improve cooperation with stakeholders (Emilsson and Hjelm, 2009). One way to expand this responsibility is thus to assume greater control of the distribution of their goods, possibly by applying coordinated freight distribution (Dablanc, 2011; Moen, 2013).

\subsection{Coordinated Freight Distribution}

Several Swedish municipalities have implemented co-distribution. In 2012, Granvik reported that, of 218 municipalities in Sweden, 8\% had already invested in co-distribution and $7 \%$ had claimed that implementation was in progress. Here, co-distribution consists of a CDC, or a singular location to which all suppliers deliver their goods and from which products are then distributed to municipal facilities. Among other things, implementing a centre for co-distribution can provide logistics support to smaller and local goods suppliers with limited delivery capacities, thereby encouraging certain suppliers to compete on a more equal basis (Granvik, 2012). 
Several similarities can be found between Swedish municipal CDCs and the concept of the urban consolidation centre (UCC). Both CDCs and UCCs operate not only to reload goods in order to increase fill rates, but also to generally facilitate change among modes (e.g. to smaller vehicles or by using alternative energy sources) used in municipal distribution. Furthermore, storage can be included in both UCCs and CDCs. Yet, there are also significant differences between the two types. A UCC supplies a city centre or commercial area with goods, while a CDC distributes to several municipal facilities across a large region. Since very few studies have described municipal CDCs and how they compare to UCCS, the literature review below describes UCCs.

UCCs constitute an established concept in research concerning urban freight transport and city logistics (Crainic et al., 2004; Taniguchi and van der Heijden, 2000; van Rooijen and Quak, 2010). One chief purpose of UCCS is to disconnect intercity transport from intra-city transport in order to make transport more efficient in general. By nature, UCCs are located closely to the geographic area they serve and receive, reload, and reorganise freight from LSPs into fewer trucks, which subsequently deliver the goods to specific delivery sites. Using a UCC can reduce vehicle-km and trips across the city, increase usage due to consolidation, and induce changes in the vehicles used (e.g. the use of lighter, cleaner vehicles that are more expedient for urban distribution) (Browne et al., 2005). Using a UCC also allows the consideration of economic, environmental, and social dimensions of sustainability; though a UCC can be costly regarding both fixed and operational costs, it can improve the efficiency of transport and afford the possibility of offering value-added services; regarding environmental concerns, a UCC can reduce emissions and noise; and from a social perspective, a UCC can increase safety and decrease barrier effects (Benjelloun et al., 2010; Crainic et al., 2004; EC, 2011; Patier and Browne, 2010). A range of value-added logistics and retail services can also be provided by a UCC, including improved return logistics, a reduced number of deliveries, and better inventory control, brokerage, and consignment (Browne et al., 2005; van Rooijen and Quak, 2010).

\subsection{Procurement of Distribution Services: A Municipal Perspective}

Moen (2013) has concluded that few municipalities run logistics operations; instead, they purchase these services. With the implementation of CDCs, the logistics flow changes and new costs emerge, which in turn increase the need to differentiate product costs from logistics costs. Swedish municipalities have traditionally not separated these costs when purchasing goods, which is very much in line with how receivers in many businesses act. These practices are clearly about to change.

Municipalities, as opposed to business, need to follow the Public Procurement Act. In this sense, applying the Public Procurement Act in purchasing logistics services is a fairly recent challenge for both municipalities and LSPs. When Swedish municipalities procure services and products, they must follow the provisions of the Swedish Public Procurement Act (2007:1091 - LOU) (Granvik, 2012; Lundberg, 2005), which is largely based on the EU Directive (2004/18/EC) concerning public procurement. By following Swedish procurement rules, municipalities meet the obligations of the EU law that supports numerous principles regarding non-discrimination, equal treatment, proportionality, mutual recognition, and transparency. In practice, this means that contracting municipalities are required to tender from more than one supplier while at the same time meet various additional demands regarding, for example, operating costs, functions, and environmental impacts.

Public procurement is an important area in which municipalities can significantly impact the environment, particularly by placing environmental demands on products and services purchased. 
These demands can, for example, also target distribution patterns and vehicle technology (Dablanc, 2011). In a similar sense, public procurement is also about setting an example, as at least one study has found: "If we are asking citizens to be environmentally responsible, public authorities should also be ready to reduce their own negative impacts" (Day, 2005, p. 202). Such could have a demonstration effect that could lead to more environmentally friendly procurement by the private sector. At the same time, municipalities can create certification schemes to be used in the process of purchasing logistics services, for example, to give certain suppliers a competitive advantage when bidding for contracts (Dablanc, 2011). These schemes make municipalities increasingly committed to select bidders who can offer, for instance, the best environmental performance.

\subsection{A Systematic Approach to Improved Organisational Environmental Performance}

Since the mid-1990s, municipalities have exhibited a trend of streamlining environmental and sustainable management, particularly by implementing EMSs based on the main principles of ISO 14001. Though this approach was first and primarily used by the private sector, it has since become widely used in the public sector as well (Emilsson and Hjelm, 2005). ISO 14001 and the standardised management approach that it implies are often criticised for being developed by and for organisations in the private sector. For example, the environmental impact from a municipality's core activities is often difficult to measure and monitor due to its indirect origin. As a consequence, municipalities often exclude these aspects from their EMSs, meaning that the organisation creates a system that only partially covers environmental performance. Procurement is one activity that gives rise to indirect environmental impacts and thus runs the risk of being excluded. Yet, since procurement can also significantly contribute to environmental impacts-potentially in positive ways, if environmental requirements are included-it is thus a potentially important issue requiring a proactive approach.

Emilsson and Hjelm (2007) also suggest that integrating environmental impacts of more indirect origins (e.g. procurement) is a matter of maturity and learning within an organisation, as well as that can be included when the basic structure and organisation of the management system is first implemented. This idea suggests the wisdom of initiating the implementation of an EMS regarding issues that are easily measured and monitored and that, once this approach has taken root, it is easier to "level up" and embrace more difficult, sophisticated issues. In general, then, a stepwise implementation of sustainability management could enhance learning and maturing within an organisation (Emilsson and Hjelm, 2009).

Stepwise expansion means, among other things, broadening the focus from a few to all internal departments, as well as to external stakeholders, in order to widen the scope and content of the system. This development is motivated by the need for mutual learning, including feedback loops, within the organisation and between the organisation, its collaborators, and other stakeholders. Employees as well as stakeholders would thus gradually mature to expand their understanding of their roles in and contributions to their organisations' overall sustainability performance.

Knowledge exchange with external actors is central to municipalities' environmental management (Fenton et al., 2014). In fact, interactive collaboration and knowledge exchange are important in all projects involving or affecting multiple actors (Albrechts, 2006). It is important to have an understanding of actors' competencies and of organisational contexts in order to enhance cooperation and mutual learning (Fenton et al., 2014). However, knowledge is of little value if not communicated 
and translated into action (Senge et al., 2006). Widening the system's perspective in this way could thereby lead to deep learning, in which knowledge is converted into a reflective practice that considers context. This is not a linear process, but a process based on feedback loops by which ideas and actions are evaluated and reconsidered. When implementing changes in distribution activities in urban areas, it is important to consider the possible of conflicting interests among affected stakeholders (OECD, 2003; Patier and Routhier, 2009). Stakeholder collaboration and communication are therefore important for successful changes in urban distribution (Lindholm, 2012; Lindholm and Thalenius, 2006; OECD, 2003). Nevertheless, national governments and urban authorities have often neglected to involve LSPs in their decision making (Browne et al., 2005).

\section{Knowledge Transfer While Implementing New Solutions}

This section presents the results of studying the initiatives in the sample of municipalities. The different approaches are reflected upon, and to some extent compared, by using the PDSA process as a structure. The cases have shown several similarities in all phases of their approaches to designing and implementing their initiatives. For example, all have engaged external consultants in performing baseline reviews (e.g. Plan) and implemented new purchasing systems to improve the operation of the solutions (i.e. Do). The three municipalities (i.e. Borlänge, Katrineholm and Värnamo) that have run their initiatives for some time have, in different ways, evaluated their approaches in order to identify what works well and what needs improvement, while the other two have put forward detailed plans regarding what to evaluate and when (i.e. Study). All cases have also reflected on how aspects of their initiatives could be further developed and changed in order to bring about more efficient distribution and purchasing (i.e. Act).

\subsection{PDSA: Plan}

All initiatives studied had performed a baseline analysis prior to establishing CDCs. These analyses were conducted by external consultants in all cases but Eskilstuna. The baseline reviews differed slightly in terms of scope and content, though they all focused on the economic potential of consolidated urban distribution. In Borlänge, the baseline review alerted the municipality of its lack of data regarding their transport demands. In response, the municipality identified the need to reclaim ownership of this information from the supplier in order to decrease their dependence upon the supplier. In Värnamo, the purpose of the baseline analysis was to develop a transport delivery plan and included an inventory of the departments' invoices in order to identify the amount of purchased goods, how often goods were purchased and delivered, and which and how many LSPs were used. Another important aim of Värnamo's analysis was to understand the number of purchasers in the municipality. Meanwhile, in Katrineholm, apart from engaging consultants for baseline analysis, establishing the initiative has been an internal process with little external input, meaning that the municipality has built an internal knowledge capacity based on pre-existing competencies and structures. To a large extent, Eskilstuna was inspired by Borlänge, since striking similarities emerged regarding the size of flow of goods and type of receivers. In fact, information from Borlänge was used to gauge terminal size, number of personnel, and IT support. Eskilstuna also took inspiration from other municipalities' solutions regarding what environmental demands to place upon the logistics services purchased. A baseline analysis of the four largest product suppliers was also made by the logistics coordinator in Eskilstuna, which showed that the number of stops at receivers could be greatly reduced. Both Eskilstuna and Södertörn experienced situations in which wholesalers did not provide them with information 
regarding transport distances, fill rates, and types of vehicles-all of which are essential to a proper baseline analysis regarding environmental impacts.

Värnamo decided to employ an experienced logistics manager to develop and establish initiatives regarding coordinated urban distribution. In this case, even if suppliers were not active in the development of the transport delivery plan, there was a continued dialogue with logistics companies throughout the planning phase in order to announce upcoming changes and discuss different solutions. Before the delivery plan was implemented, the logistics manager and LSP that won the bid to operate the CDC visited sites at all $145-150$ receivers in order to assess local physical conditions (e.g. accessibility). Among many other reasons for doing this, an important one was to determine the size of trucks that could access the different facilities.

In Borlänge, an employee with industrial logistics knowledge formed a group including the departmental managers of both the purchasing and environmental departments. The municipality decided early on to purchase the logistics services, yet also to be active and stipulate its conditions. As with Värnamo, Borlänge maintained an active dialogue with the LSPs that had secured the inclusion of their viewpoints. After a year's time, the project received financial support from the City Council and the Swedish Energy Agency. A need for increased knowledge at delivery points (e.g. schools) was identified, as were improved computer and purchasing skills of most employees, which were low when the initiative was established and when new purchasing routines were implemented. The initiative was introduced fairly quickly; within 3 months, all involved parties had been informed, introduced, and trained.

In Södertörn, experience with the logistics industry regarding reasonable environmental demands was gained by interviewing 10 logistics providers. As a result, the demands placed upon biogas fuel for all vehicles in the solution have been realised, and electric vehicles have been identified as the next step forward. Biofuel is also used in full scale in Eskilstuna.

\subsection{PDSA: Do}

All cases stressed the importance of communication in the implementation of new initiatives. Though communication was structured in different ways in different cases, all cases emphasised the importance of continued dialogue and inclusive processes for the implementation to succeed. One way of communicating is to train employees, as was done in Borlänge; another way is to discuss the new approach and its function with affected actors, as was done in Värnamo and Eskilstuna. Katrineholm and Eskilstuna chose a stepwise implementation approach to their consolidation in order to induce a parallel learning process.

The initiative in Borlänge was launched in full scale without any test period, though training programs were introduced to enhance its implementation, and receivers and purchasers were educated regarding how to manage the changed purchasing and delivery conditions. For example, less frequent deliveries demanded increased planning skills. Furthermore, a new tool for purchasing was introduced. However, a major setback in implementation was that the technology was not fully developed and could therefore not support electronic purchases, which resulted in a reversion to older technologies. In 1999, Borlänge was the first municipality to implement these changes, while cities with subsequent implementation show that purchasing supporting IT services is no longer problematic. 
Värnamo held no formal training sessions for its staff or politicians. Instead, its strategy was to gain acceptance for and spread knowledge about the new concept through a reference group and by meeting all purchasers and receivers of the goods.

The approach in Katrineholm differed slightly from that of the other two cases. There, the head of the unit for food and transport services coordinated the CDC, while the City Council determined the budget and goals for the initiative, the progress of which was regularly reported to the City Council. Purchasers ordered their goods via the electronic system that was, as mentioned earlier, affiliated with the initiative. Due to Katrineholm's stepwise introduction and its approach that involved departing from pre-existing structures and routines, this municipality has primarily made only minor adjustments to their former activities and required no special training.

In Södertörn, information exchange was a significant challenge due to the large size of the initiative and the amount of people who needed to be informed, convinced, and educated about the changes to be made. The respondent from Eskilstuna stressed the need for information, that there are no risks posed by providing people within the municipality with too much information, and that the same information needed to be provided continually throughout the process. These priorities underscore the importance of having built-in feedback loops throughout the process, by which information as well as knowledge and experiences can be reflected upon and induce further development. At the same time, both Eskilstuna and Södertörn have experienced a lack of basic logistics knowledge within their organisations, which at times became frustrating as people became sceptical of the solution due to lacking knowledge regarding the flow of both goods and information.

\subsection{PDSA: Study}

Borlänge, Katrineholm, and Värnamo have each reported benefits from their respective implementations in terms of decreased noise levels, increased safety, and reduced emissions. In Borlänge, the amount of stops at most receivers dropped by $50-75 \%$, depending on the size of the receiver. All three cities have also reported more efficient coordination in purchasing. A survey conducted in Borlänge revealed that both receivers and purchasers were generally pleased with the new solution, while evaluations in Värnamo have shown that the more coordinated distribution has succeeded from an economic perspective and that there have been no increases in transport costs for purchasers or units. At the same time, Katrineholm experienced less goods waste and a decreased need for storage.

Borlänge evaluated their initiative in both 2000 and 2001, during which period the number of suppliers increased from eight to 15 , the amount of local suppliers increased, and more ecological products were purchased. Since these evaluations did not find suppliers' transport cost data to be reliable, the economic potential of the initiative has not been estimated. Over the past few years, Borlänge's coordinated urban distribution has not reported any major progress or further development. In fact, the number of minor suppliers has drastically reduced due to reasons not yet clearly identified. Furthermore, the LSP has started to deliver later in the day, at times with more traffic and pedestrians both on the street and around the receivers, which means, among other consequences, that the receivers' other activities must be rearranged.

Värnamo's initiative is evaluated continually, primarily by annual visits from the municipal logistics manager to each receiver in order to evaluate what improvements are needed. For the same purpose, the municipal logistics manager also attends a wide range of meetings with purchasers, janitors, 
kitchen staff, and other municipal internal actors, in order to understand the perspectives of different actors involved in delivery and purchasing routines. The results of the evaluations and follow-ups are communicated via reference groups and internal reports to the City Council. There is also continued communication with the LSP responsible for the deliveries of goods to the units.

At the time when this study was conducted, no evaluation or formal follow-up of the coordinated approach to transport in Katrineholm had been performed. One reason for this was that its municipal initiative was developed among pre-existing municipal activities and considered to be routine. Yet, there is continued informal personal contact between the coordinator of the initiative and the purchasers, departments, and politicians, during which results and ideas for improvement are discussed.

Although the establishment of CDCs in the municipalities studied were generally perceived to be positive, numerous challenges and problems were also identified. Storage is one such example, given the larger quantities delivered and the handling of heavier parcels. In Värnamo, for instance, some kindergartens had problems with storing a whole week's worth of food in their fridges. Other cities experienced communication problems between receivers and the CDC regarding opening hours, among other issues. Furthermore, Borlänge and Södertörn unexpectedly experienced no decrease in suppliers' prices for the products, despite that the number of delivery points was drastically reduced. Katrineholm experienced problems in tracing responsibility for the goods within the transport chain. In this sense, if a parcel were missing, then it was difficult to identify where in transport it was lost and which actor to hold responsible.

Due to the late implementation of initiatives in Eskilstuna and Södertörn, no follow-up investigations of the results are available. However, Eskilstuna plans meetings with its logistics each quarter to discuss the initiative's further development. In its contract with the logistics company, the municipality is afforded access to information regarding fuel consumption, driver behaviour (speed) and number of stops. Furthermore, Eskilstuna is currently conducting studies at three types of receivers in order to evaluate how the new solution influences the use of personnel resources. Plus, both Eskilstuna and Södertörn advanced the need for evaluations, and both plan to monitor how product prices change over time.

\subsection{PDSA: Act}

In this study, all initiatives were recognised nationally as being proactive, innovative approaches. Borlänge, Katrineholm, and Värnamo host study visits for other municipalities, consultants, and suppliers seeking inspiration and ideas for developing their own coordinated urban distribution. As such, sharing their experiences and knowledge with other actors has been an important part of their work. They have all gained experience and identified both drawbacks and strengths in their individual approaches, which has led to the development of more mature solutions for municipal purchasing and transport. Borlänge has come to understand that its purchasing performance must be improved before the end of the contract period by, for example, being more precise regarding follow-up.

One advantage of Katrineholm's approach was its being designed to make use of pre-existing structures, budgets, and activities. Nevertheless, the coordinator of the initiative considered that the planning should have been more thorough and strategic. For example, the CDC was accommodated in facilities originally developed for other activities, which the respondent reflected could have been improved with more strategic planning to consider other options or develop more suitable facilities 
before enacting the initiative. When developing a similar concept in the future, the respondent stated that planning needs to be more strategic and farsighted and that politicians need to express a clearer vision. This respondent added that the communication and dissemination of knowledge regarding the initiative should have been better during the planning phase, perhaps by presenting the vision and changes in purchasing routines that the implementation of such a solution implies.

Based on their experiences, all municipalities studied here have reflected on the future development of their initiatives and generally see potential in developing regional solutions that include neighbouring municipalities. To some extent, Borlänge has already done this, though they recognise that the solution would benefit from including more municipalities. Katrineholm also identifies future potential in cooperating with not only neighbouring municipalities, but also other public purchasing bodies (e.g. the county council). Eskilstuna also sees significant potential and has started to use its terminal for other types of goods (e.g. the municipality's furniture and equipment, which it stores). The terminal staff are expected to have a more uniform workload, while the sharing of resources between units can improve local information exchange.

Borlänge reflected on other expansions of their initiative, such as increasing tenders to both include more products (e.g. office materials, cleaning equipment, and return transport) and to increase the number of receivers (e.g. by including private schools, smaller shops, gas stations, and restaurants). The municipality wanted to support smaller suppliers and has identified several strategies that could facilitate what it calls "a system's change". One strategy is to ask for tenders by not specifying the total amount, but instead asking for possible amounts; another is to increase the number of product categories by increasing the level of detail. Yet another strategy is to purchase larger quantities, since some smaller companies can deliver only full pallets, and to divide consignments at the CDC.

Optimising routes was another area ripe for future development, as mentioned by the representatives of Borlänge and Värnamo. They see future cost-saving potential in decreasing the time that the drivers spend on the road. According to Värnamo, along with an increased load factor, this strategy could be important for saving both money and the environment.

Eskilstuna has provided a detailed plan for the expansion of its initiative regarding the product groups included. In identifying the largest potentials in that area, it started with food, but with the expiration of current contracts, plans to expand the scope of the initiative to include other products. It has also considered night delivery in the development of the initiative, as soon as receivers and drivers at the logistics company become more familiar with each other.

\section{Discussion}

\subsection{Improved Sustainability with CDCs and Changed Purchasing Routines?}

Due to the insufficiency of follow-ups and the complexity of measurement, it is impossible to state with any accuracy that the implementation of CDCs has benefited sustainability. All municipalities studied-both those in the more general desktop study and those in the interview study-have aims and goals seeking a better environment, social sustainability, and economic benefits. They also seek to decrease traffic and transport work, as well as increase the consolidation rate, both in line with findings from city logistics literature (e.g. Browne et al., 2005). Though municipalities describe these goals, few present actual numbers regarding how large the benefits have been or the methods applied in their 
calculations. One reason for this could be that the gains have been so slight or even negative and thus not published. Another more likely explanation is that no actual follow-up has been performed to capture the change in number of vehicles, vehicle-km, and tonne-km, among other characteristics. However, the newly implemented initiative in Eskilstuna could provide some guidance, since its contract with the logistics supplier stipulates that the LSP must provide the city with certain statistics (e.g. vehicle-km and number of stops). It would be interesting to further study these aspects to increase the current understanding of how municipalities monitor their performance and use that information in the future management and development of their solutions. As indicated earlier, valuing impacts of more indirect origins (e.g. EMSs) has proven difficult and could be related to organisational maturity, while more direct effects are easier to measure and evaluate. On this point, findings from municipalities contacted provide some insight. For instance, Borlänge presented followups for evaluating the type of suppliers used to show that its initiative makes increasing the share of both local suppliers (e.g. with reduced transport distances and by supporting local economic growth) and eco-labelled products. Both Eskilstuna and Södertörn plan to monitor the development of costs of purchased products, while Eskilstuna also plans to investigate the altered use of human resources at receivers in order to obtain information important to further developing the initiative's business model. The positive outcomes of establishing CDCs experienced by municipalities are in line with how the outcomes from establishing UCCs are commonly presented in the literature. The measures taken relate to both environmental and security aspects and contribute to positive effects in several areas. The chief result is decreased number of deliveries to receivers, which has led to increased security, decreased emissions, and reduced economic gains. In Eskilstuna, it is thus evident how change can significantly improve the delivery service and work environment of receivers.

All of the municipalities studied here have revised their purchasing routines, which they believe has resulted in a more efficient process that could lead to improved sustainability. Among other things, changed purchasing routines have induced better overview of inventories and clarified the need and usage of products in municipal departments. We can thus expect an additional decrease in environmental impact due to the decreased risk of inventory obsolescence (e.g. products not identified on shelves will expire and require disposal). For example, Katrineholm experienced less waste as well as a decreased need for storage, both of which have resulted in environmental as well as economic benefits. All municipalities have placed environmental demands on the logistics services purchasednamely, regarding e.g. vehicle technology and eco-driving training.

Yet, public procurement also clearly involves setting an example (Day, 2005). These municipalities' use of CDCs offers them a better understanding of and arguments for placing demands on other actors to take action in order to improve urban distribution.

The implementation of coordinated distribution indicates that municipalities have expanded their scope of environmental management by applying other measures. The traditional focus of municipalities on, for example, rules and regulations that influence the flow of goods (Benjelloun et al., 2010; Patier and Browne, 2010) has expanded to also include aspects such as consolidation, route optimisation, stakeholder collaboration, and demands placed upon procuring logistics services. Similarities between the municipalities studied here are clear in how they identify synergy by combining different measures to improve distribution in urban areas. The integration of environmental impacts of more indirect origins (e.g. in purchasing) also arguably indicates maturity and learning in the municipality and its environmental management, as is in line with Emilsson and Hjelm (2007). The 
need to combine different technological, logistical, and policy measures in order to reach more sustainable logistics in urban areas is also identified as necessary to attaining sustainability in cities (Anderson et al., 2005; Browne et al., 2005).

Results might also indicate that the degree of maturity among municipalities' environmental management differs, since their actions can target different sustainability perspectives. Emilsson and Hjelm (2009) have identified a shift toward sustainability management possibly due to organisational maturity. However, despite the sustainability gains from changed purchasing routines and the inclusion of CDCs, no clear linkage between municipalities' EMSs and such actions could be identified in this study. Nevertheless, several of the cities studied have EMSs in place and should be accustomed to working with feedback loops to enhance maturity and development of sustainability management in organisations. Adopting a cyclic approach in other areas might also make it easier to apply purchasing and CDC initiatives.

Unfortunately, we are unable to provide any additional evidence of the connection between EMSs and proactive approaches to purchasing. However, the PDSA structure proved useful for visualising the dissemination of knowledge and for identifying and presenting variations in collaborative actions between different phases of CDC development and implementation. All cases concur on the importance of having continued communication with stakeholders from an early stage of the planning process as a means to understand receivers' local conditions and stakeholders' needs and concerns. These conclusions are in line with what Hjelm et al. (2011) discuss regarding the importance of designing approaches adapted to local contexts and users in order to ensure that initiatives will be effective. While knowledge can be transferred in different ways and in different phases of establishing and operating the initiatives, even if the municipalities in this study have suggested that these processes are primarily internal regarding their development and implementation, other examples showcase external knowledge transfer (Figure 1).

\subsection{Knowledge Dissemination and Collaboration}

Changes in urban distribution often involve and/or affect numerous stakeholders (Benjelloun et al., 2010), and literature addressing city logistics argues that stakeholder collaboration and communication are vital to city logistics initiatives' success (Lindholm and Thalenius, 2006; Lindholm, 2010; OECD, 2003). Moreover, literature addressing environmental management confirms this need by, for example, prioritising the understanding of actors' competencies and organisational contexts in developing effective concepts (Hjelm et al., 2011). This idea is also supported by Senge (2006), who has argued that widening system limitations can induce deep learning, in which knowledge is converted into a reflective context that considers practice. Empirical findings from the five cases indicate the importance of communication and collaboration with external actors, as well as of internal communication. However, the development of CDCs in the cities studied has primarily been handled as an internal concern. That said, the cities studied have held discussions with other stakeholders in order to understand their perspectives and communicate the changes that will accompany new freight distribution solutions.

Both Eskilstuna and Södertörn stress the importance of building basic logistics knowledge within municipalities and that such is necessary not only in the future development of their initiatives, but also in their communication with businesses in the municipality regarding future city logistics initiatives. However, the type of knowledge needed must first be identified. Today, most logistics 
research targets business logistics, though the future will demand increased logistics knowledge that can be applied by other actors in society.

According to the literature, local authorities have often failed to involve LSPs in the decision-making process regarding urban distribution (Browne et al., 2005). As such, the involvement of LSPs in municipalities represents a welcome change in how municipalities manage urban distribution. Three of the municipalities studied here stated that a key to their success was close collaboration and communication with internal actors and the LSPs. By the same token, the lack of such communication has been identified as a barrier to development in the other cases.

However, despite the importance of internal communication, capacity-building seems unstructured, which results in limitations regarding knowledge transfer. When collecting empirical data, respondents identified only one person in the municipality, who was perceived as the sole person who possessed detailed information and contacts concerning the coordinated approach as well as had an overview of the initiative. This silo of knowledge is an obvious vulnerability of these initiatives, since such an arrangement makes spreading knowledge among municipalities difficult, if not impossible. Capacitybuilding and knowledge transfer among different initiatives also show room for improvement. No structured method for taking into account the experiences of other municipalities seems available, even though all municipalities studied offer guided visits and seminars for other municipalities and consultancy firms.

The case of Eskilstuna provides a solution that can increase integration among departments within the municipality by offering storage for furniture and by facilitating other forms of internal distribution, among other methods. Increasing integration within municipalities is another recommendation by respondents in this study, since doing so can assess whether the use of a CDC can facilitate such integration.

\section{Concluding Remarks and Opportunities for Further Development}

A large spread exists among the population size of municipalities that have implemented CDC solutions, as well as regarding the type of municipalities that have implemented consolidated distribution. These spreads indicate that neither type nor size of the municipality determines whether the municipality can implement consolidated distribution.

This study has provided valuable insights into how municipalities can and do contribute to more sustainable urban freight distribution. Information exchange and knowledge transfer are described as paramount to the success of city logistics, an observation evident in literature (Lindholm and Thalenius, 2006; OECD, 2003) and municipalities studied here. However, few studies have provided insight into how and when this exchange should be carried out. Our findings from interviews with representatives from five Swedish municipalities stress the importance of such exchanges during all phases of the development and implementation of the initiative, as well as that the PDSA can be an appropriate tool for systematising and evaluating the information exchange occurring in different phases. Our study also highlights the importance of internal information exchange, an idea not widely discussed in city logistics literature. Along with increasing logistics knowledge within municipal organisations, it would be interesting to conduct a more thorough study of communication in an ongoing project regarding the implementation of a new CDC that included LSPs to a greater degree. 
The future development of CDC concepts aims to increase scales in order to gain more economicand perhaps environmental-benefits. The municipalities studied here have already started to reflect such goals by including larger numbers of receivers, municipalities, and types of goods. There are, however, several challenges or potential drawbacks with large systems. For example, different product groups need different techniques for handling goods. Furthermore, if the CDC is operated by the municipality and thereby committed to a specific $C D C$, then there could be problems with storage. If everything, including the operation of the $C D C$, is purchased via procurement processes, then there can be more opportunities for flexible solutions given any new tender period.

Municipal use of CDCs is not a new phenomenon; indeed, in Sweden, it began in Borlänge in 1999. However, research within the field remains nearly non-existent. One area that requires further investigation is the possibility of introducing more value-added services to the CDC. In UCCs, valueadded services can provide several large-scale advantages (McKinnon et al., 2010; van Rooijen and Quak, 2010). As initiatives continue to grow, these advantages also grow larger and can provide several economic and environmental benefits. The municipalities studied here described the use of valueadded services (e.g. return handling and storage) executed in the terminal instead of, for example, at the receiver. Yet, value-added services have the potential to be used to even larger extents. For example, it seems that only a few municipalities currently have drivers unloading and placing goods in storage at receivers or for brokerage and consignment. However, knowledge regarding how to select, design, and adapt value-added services for inclusion with different CDCs remains scarce and the experience limited, underscoring the need for more research on this topic. Furthermore, responsibilities for municipalities do not end with their own transport. Municipalities can also influence the flow of other goods within cities such as Lucca, Italy, where the city charges a fee for all vehicles that enter the city centre and has implemented an alternative and attractive solution for the delivery of goods there: a UCC. As such, it is time for Swedish municipalities to begin considering taking this one step further, though further research is needed in order to design potential initiatives suitable for the Swedish market.

\section{References}

Albrechts, L. 2006. Bridge the Gap: From Spatial Planning to Strategic Projects. European Planning Studies 14, 1487-1500.

Allen, J. and Browne, M. 2010, Considering the relationship between freight transport and urban form. Green logistics. University of Westminster London. UK.

Behrends, S., Lindholm, M., Woxenius, J., 2008. The impact of urban freight transport: A definition of sustainability from an actor's perspective. Transportation planning and technology. 31(6), 693-713.

Benjelloun, A., Crainic, T. G., and Bigras, Y., 2010. Towards a Taxonomy of City Logistics Projects. Procedia - Social and Behavioral Sciences. 2(3), 6217-6228.

Browne, M., Woodburn, A., Sweet, M., Allen, J., 2005. Urban freight consolidation centres, Final report. Transport Studies Group, University of Westminster for the Department for Transport.

Crainic T.G., Ricciardi, N., Storchi, G., 2004. Advanced freight transportation systems for congested urban areas. Transport Research part C. 12(2), 119-137. 
Dablanc, L., 2007. Goods transport in large European cities: Dificult to organize, difficult to modernize. Transport Research Part A, 41(3), 280-286.

Dablanc, L. 2011. City distribution, a key element of the urban economy: guidelines for practioners, in Macharis, C. and Melo, S. (Eds), City Distribution and Urban Freight Transport: Multiple Perspectives, Edward Elgar Publishing, Cheltenham, UK.

Day, C. 2005. Buying green: the crucial role of public authorities, Local Environment, The International Journal of Justice and Sustainability, 10(2), 201-209.

Deming, E.W. 1982. Out of the crisis. Massachusetts Institute of Technology. Cambridge, Massachusetts.

EC, 2007. Green paper: Towards a new culture for urban mobility, 551, Directorate-General for Energy and Transport, Brussels, Belgium.

EC, 2011. EC white paper: Roadmap to a single European Transport Area.

Eriksson, O., Carlsson Reich, M., Frostell, B., Björklund, A., Assefa, G., Sundqvist, J-O., Granath, J., Baky, A., Thyselius, L., 2005. Municipal solid waste management from a systems perspective. Journal of cleaner production. 13, 241-252.

Ely, M., Anzul, M., Friedman,T., Gardner, D., McCormack Steinmerz, A. 1993. Kvalitativ forskningsmetodik i praktiken -cirklar inom cirklar (Translated by Liungman C.,G.). Studentlitteratur, Lund.

Emilsson, S., Hjelm, O. 2005. Development of the use of standardised environmental management systems in local authorities. Corporate Social Responsibility and Environmental Management 12, 144156.

Emilsson, S., Hjelm, O. 2007. Managing Indirect Environmental Impact Within Local Authorities' Environmental Management Systems. Local Environment 12, 73-86.

Emilsson, S., Hjelm, O. 2009. Towards sustainability management systems in three Swedish local authorities. Local Environment 14(8), 721-732.

English, M. R .1999. Environmental Decision Making by Organizations: Choosing the Right Tools. In Better Environmental Decisions- Strategies for Governments, Businesses, and Communities. Sexton, K., Marcus A. A., Easter, K. W., Burkhardt T. D. (eds). Island Press:Washington D.C

Fenton, P., Gustafsson, S., Ivner, J., Palm, J. 2014. Sustainable Energy and Climate Strategies: lessons from planning processes in five municipalities, Journal of Cleaner Production (2014), doi: 10.1016/j.jclepro.2014.08.001.

Granvik, M. 2012. The Localization of Food Systems - An Emerging Issue for Swedish Municipal Authorities, International Planning Studies, 17(2), 113-124.

Gupta, V. 2006. Beyond PDCA - A new process management model. Quality Progress. 39, 45-52. 
Hjelm, O, Gustafsson S, Cherp A. 2011. From tool technique to tool practice. Experiences from the project SEAMLESS: Strategic Environmental assessment and management in local authorities in Sweden. Blekinge Tekniska Högskola. Forskningsrapport Nr: 2011:01. Rapport nr 9 från MiStprogrammet.

ISO, 2004. Environmental management systems- General guidelines on principles, systems and supporting techniques (ISO 14004:2004, IDT).

Kahn, J. 2013. What role for network governance in urban low carbon transitions? Journal of cleaner production. 50, 133-139.

Kennedy, C., Miller, E., Shalaby, A., Maclean, H. and Coleman, J. 2005. The Four Pillars of Sustainable Urban Transportation. Transport Research. 25(4), 393-414.

Levett, R. 1997. Tools, Techniques and Processes for Municipal Environmental Management. Local Environment 2, 189-202.

Lindholm, M. 2012. Enabling sustainable development of urban freight from a local authority perspective. PhD thesis. Department of technology management and economics. Chalmes university of technology. Gothenburg. Sweden.

Lindholm, M. and Blinge, M. 2014. Assessing knowledge and awareness of the sustainable urban freight transport among Swedish local authority policy planners. Transport Policy. 32, March 2014, 124-131.

Lindholm, M. and Thalenius, J., 2006. Analys av miljöstrategiska logistikprojekt. TFK Rapport 2006:5. Stockholm. (Analysis of environmentally strategic logistics projects, Report from TFK) (In Swedish)

Lindqvist, A. ,von Malmborg, F., 2004. What can we learn from local substance flow analyses? The review of cadmium flows in Swedish municipalities. Journal of Cleaner Production. 12, 909-918.

Lundberg, S., 2005. Restrictions on Competition in Municipal Competitive Procurement in Sweden. International Advances in Economic Research 11 (3), 329-342.

Martinsen, U., Björklund, M., Huge Brodin, M., 2012. The Importance of Stakeholder Relationships in City Logistics Projects. Conference proceeding at the NoFoMa conference. Finland.

McKinnon, A., 2010, Environmental sustainability: a new priority for logistics managers. In: McKinnon, A., Browne, M. (Ed.) Green Logistics Improving the environmental sustainability of logistics., Kogan Page, India.

Moen, O. 2013. Samordnad varudistribution 2.0. Logistik I kommunens varuförsörjningskedja. (Coordinated freight distribution, Logistics in municipalities supply chain). Studentlitteratur, Lund. (InSwedish)

OECD, 2003. Delivering the Goods - 21st Century Challenges to Urban Goods Transport. Paris.

Patier, D., Routhier, J.L., 2009. How to improve capture of urban goods movement data. Bonnel, P. Lee-Gosselin, M., Zmud, J., Madre, J-L. Eds. in: Transport Survey Methods: Keeping Up with a Changing World. 
Patier, D., Browne, M. 2010. A methodology for the evaluation of urban logistics innovations. Social and behavioural science. 2, 6229-6241.

Senge, P., CO Charmer, Jaworski, J., Flowers, B.S. 2005. Presence. Exploring profound change in people, organizations and society. Nicholas Brealey Publishing, London.

SALAR, 2012. Classification of Swedish Municipalities, 2011.

http://www.skl.se/kommuner och landsting/fakta om kommuner/kommungruppsindelning.

(Accessed on the $18^{\text {th }}$ of June 2012)

Stathopoulos, A., Valeri, E., \& Marcucci, E., 2012. Stakeholder Reactions to Urban Freight Policy Innovation. JTG. 22, pp. 34-45.

Statistics Sweden, 2011. Swedish population statistics.

http://www.scb.se/Pages/TableAndChart $\quad 308468$.aspx (in Swedish). (Accessed on the $18^{\text {th }}$ of June 2012)

Taniguchi, E. and van der Heijden, RECM. 2000. An evaluation methodology for city logistics, Transport Reviews, 20 (1), 65-90.

Taniguchi, E. \& Tamagawa, D., 2005. Evaluating City Logistics Measures Considering the Behavior of Several Stakeholders. J. Eastern Asia Society for Transportation Studies. 6, 3062-3076.

UNCED (United Nations Conference on Environment and Development). 1993. Agenda 21: Program of action for sustainable development. New York: United Nations Department of Public Information.

Van Rooijen, T. and Quak, H.J. 2010. Local Impacts of a new Urban Consolidation Center -the case of Binnenstadservice.nt, Procedia Social and Behavioural Sciences. 2(3), 5967-5979.

\section{Information regarding the municipalities}

Bergqvist, R. and Woxenius, J. 2009. Godstransportstudie för Värnamoregionen. Förutsättningar för kombinerade transporter. (Study of freight transports in the Värnamo region, Precondition for combined transports) (In Swedish)

Borlänge municipality. 2001. Samordnad livsmedelsdistribution, 2001, Borlänge kommun. (Consolidated distribution of food, 2001, Borlänge municipality)

Hultgren, J. and Andersson, S. G. 2012. Förstudie avseende samordnad varudistribution på Södertörn (Preinvestigation of coordinated distribution at Södertörn).

Vägverket. 2001. Miljöeffekter av samordnad livsmedelsdistribution i Borlänge, Gagnef och Säter. Publ. 2001:12. Vägverket. Sweden. (Environmental effects from consolidated distribution in Borlänge, Gagnef and Säter)

Borlänge municipality homepage: www.borlange.se (Accessed on the $25^{\text {th }}$ of March 2014)

Halmstad municipality homepage: www.halmstad.se (Accessed on the $25^{\text {th }}$ of March 2014)

Katrineholm municipality homepage: www.katrineholm.se (Accessed on the $25^{\text {th }}$ of March 2014)

Nacka municipality homepage: www.nacka.se (Accessed on the $25^{\text {th }}$ of March 2014)

Södertörn municipalities' mutual homepage: www. Sodertornskommunerna.se (Accessed $9^{\text {th }}$ of September 2014) 
Uppsala municipality homepage: www.uppsala.se (Accessed on the $25^{\text {th }}$ of March 2014) Värnamo municipality homepage: www.varnamo.se (Accessed on the $25^{\text {th }}$ of March 2014) Växjö municipality homepage: www.vaxjo.se (Accessed on the $25^{\text {th }}$ of March 2014) 